\title{
Investigation and management of iron deficiency anaemia in general practice: a cluster randomised controlled trial of a simple management prompt
}

\author{
E C M Logan, J M Yates, R M Stewart, K Fielding, D Kendrick
}

Postgrad Med J 2002;78:533-537

See end of article for authors' affiliations

Correspondence to: Dr E C M Logan, King's Mill Centre for Healthcare Services, Sutton-in-Ashfield, Notts NG17 4JL, UK; elisabeth.logan@ kmc-tr.nhs.uk

Submitted

19 February 2002

Accepted 19 June 2002
Background: Iron deficiency anaemia (IDA) remains the most common cause of anaemia and is frequently secondary to occult gastrointestinal blood loss requiring further investigation. The study was designed to prospectively assess the adequacy of investigation of IDA and to establish whether a simple computerised prompt would increase the completeness of investigation of patients presenting to their general practitioners.

Patients and methods: All men aged $>20$ and women aged $>50$ newly found to have a probable IDA $(n=431)$ in primary care were randomised according to general practice $(n=89)$ to one of two computer generated prompts, by the haematology laboratories in two large district general hospitals. Data were collected 12 months after the index date. The primary outcome measure was the adequacy of investigation of the cause of anaemia. Multiple logistic regression was used to analyse each binary outcome.

Results: Two hundred and three (47\%) of 431 patients presenting to their general practitioner with an IDA were adequately managed and 140/357 (39\%) of patients who were otherwise fit for investigation had no tests at all. Twenty one (17\%) of 125 patients who did have adequate investigation at the time of presentation were found to have colorectal cancer. Only $30 \%$ of patients had a confirmed diagnosis within 12 months.

The prompt did not affect the level of investigation (odds ratio $0.88,95 \%$ confidence interval (Cl) 0.60 to $1.29, p=0.52$ ). The initial prescribing of oral iron was improved (odds ratio $2.19,95 \% \mathrm{Cl}$ 1.27 to $3.77, p=0.005$ ), but not the documented prescribing of a full therapeutic course or the use of follow up blood counts.

Conclusions: The investigation and management of IDA presenting in general practice remains inadequate and is not improved by a simple management prompt. r

ron deficiency is the most common cause of anaemia and affects about $1 \%$ of the UK population a year. ${ }^{1}$ It is generally a result of blood loss from the gastrointestinal tract or the uterus and is frequently a sign of serious underlying disease. Consequently, appropriate management requires not only the prescription of an adequate course of iron to replenish iron stores, but also investigations to find an underlying cause in all patients fit and willing to undergo further tests. ${ }^{2-5}$ The response to iron therapy should be monitored to ensure the correct diagnosis, patient compliance, and resolution of the anaemia.

Several studies have examined the management and outcome of iron deficiency anaemia (IDA) in patients referred for specialist investigation, ${ }^{6-11}$ but few studies have looked at the management and outcome of episodes of IDA presenting in the community. ${ }^{12-14}$ An earlier retrospective study in one health district showed that many patients presenting with IDA were not being fully investigated, and as a result some cases of serious disease were being missed. ${ }^{15}$ We have therefore carried out a prospective study to assess the adequacy of investigation of IDA and to establish whether a simple computer generated prompt would increase the completeness of investigation of patients presenting in general practice. We have examined the effect of the prompt on the treatment and resolution of the anaemia and on the clinical outcome at 12 months.

\section{METHODS}

Selection of patients

The study population comprised men over 20 years and women over 50 years with probable IDA, defined as a haemo- globin level of $120 \mathrm{~g} / \mathrm{l}$ or below (men) or $110 \mathrm{~g} / \mathrm{l}$ or below (women), together with a mean cell volume of less than $82 \mathrm{fl}$ in district 1 or $78 \mathrm{fl}$ in district 2 and red cell count not exceeding $5.5 \times 10^{12} / \mathrm{l}$ (the blood autoanalysers used by the two hospitals had different normal ranges). Women under 50 years were excluded because the management of IDA in the reproductive years differs from that in later years due to the high incidence of menstrual blood loss contributing to the anaemia. Patients who had been found to be anaemic within the previous 12 months or with known abnormal red cell indices such as those due to a haemoglobinopathy were excluded.

\section{Practice selection, randomisation, and intervention procedure}

One hundred and twelve general practices that had sent full blood count requests to the two hospital laboratories in 1996-97 were included. The general practices were in two adjacent health districts and all had direct access to both radiology and endoscopy services.

Practices were randomised after first being stratified by district and by practice size. Randomisation was carried out independently by a third party using random number tables and blinded to the practice details.

Following identification of a patient from their blood indices, the laboratory computers in each hospital were programmed to print the appropriate prompt allocated to that

Abbreviations: $\mathrm{Cl}$, confidence interval; IDA, iron deficiency anaemia 


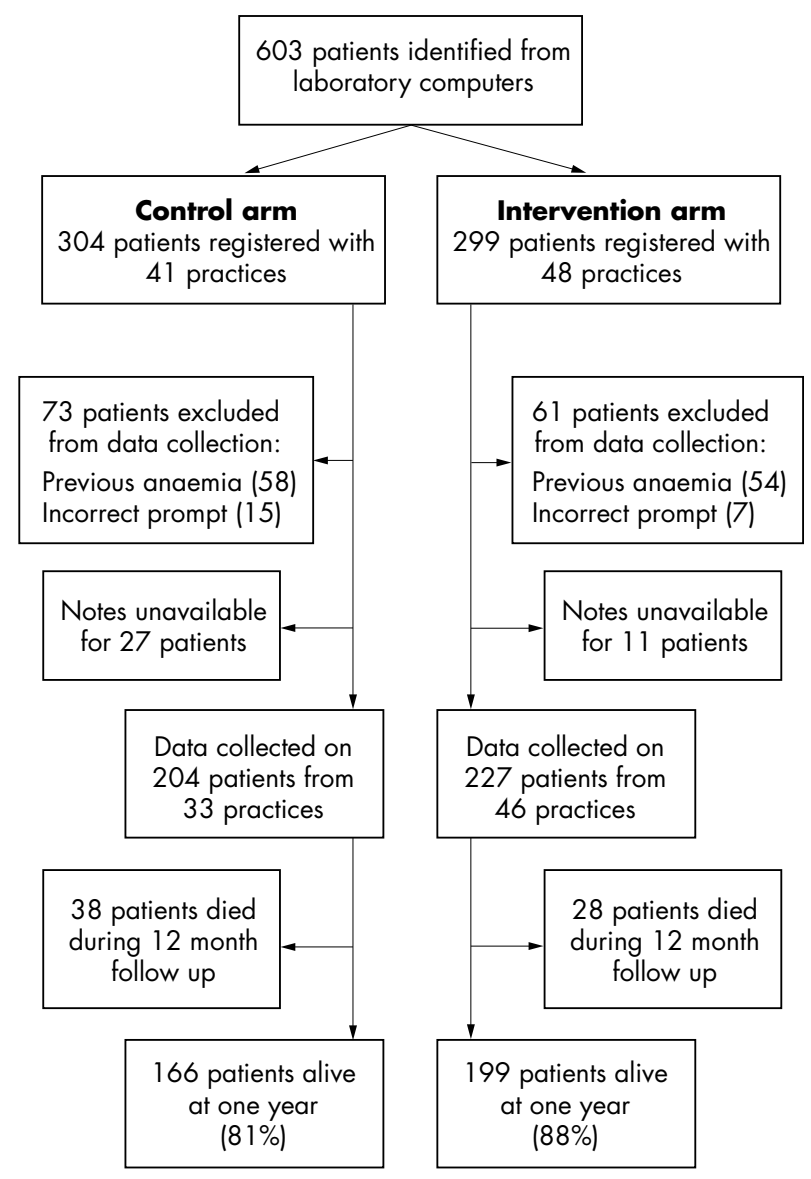

Figure 1 Flow chart of patients identified from hospital laboratory computers.

practice, on the report showing the results of the request for a full blood count. The control prompt stated: "consistent with iron deficiency-? cause" and the intervention prompt stated: "consistent with iron deficiency-? cause. Suggest treat with ferrous sulphate, $200 \mathrm{mg}$ tds [three times a day] for 4 months but check response in 3-4 weeks. Simultaneously investigate cause. Consider barium enema to exclude colorectal problems".

All previous comments on report forms were withdrawn 12 months before the trial commenced in June 1997 and the prompts continued to be printed for six months after it closed in March 1998.

\section{Access to relevant information}

Data collection started in September 1998. Permission to access relevant medical records was requested from general practitioners by letter, outlining the aims of the trial and confirming approval of the study by the local research ethics committees and the local medical committees. Three practices subsequently requested patient consent, which was obtained from five of seven patients. Access to the records of deceased patients was obtained from the two health authorities, and hospital records were also used where necessary. All data were gathered a minimum of 12 months from the date when the anaemia was first detected and entered into an Access database.

\section{Outcome measures}

The primary outcome measure was adequate management, instigated within three months of the incident anaemia. This was defined as any of the following:

- A satisfactory upper and lower gastrointestinal investigation.
- A single gastrointestinal investigation which showed cancer, a bleeding ulcer, coeliac disease in men under 50 , or extensive diverticular disease in patients over 75 with no upper gastrointestinal symptoms.

- Other investigations (for example, gynaecological, renal) revealing causative pathology.

- Documented causative pathology (for example, menorrhagia)

- No investigation because unfit or died before planned investigation completed.

Patients who had a single gastrointestinal investigation without significant pathology, or no investigation and no documented reason, were classed as "not adequate", as were those who refused. All clinical diagnoses which may have contributed to the anaemia were recorded.

As a secondary outcome measure, data on the dose and duration of therapy with iron were recorded along with any blood count requested within six weeks of the anaemia and the last haemoglobin level within the 12 month follow up period.

\section{Calculation of sample size}

Initial calculations were based on the results of the previous study and the primary outcome measure of the trial. We assumed that approximately $50 \%$ of patients in the control arm might be adequately investigated, with a possible increase to $70 \%$. The sample size was increased to allow for clustering, using a cluster size of 3-4 and an intracluster correlation factor of $0.05 .{ }^{16}$ In addition the sample size was increased because a possible $20 \%$ of patients would not be fit for investigation due to age or comorbidity. These calculations indicated that a sample size of 180 per trial arm would be sufficient for $90 \%$ power and a 5\% significance level.

\section{Statistical analysis}

Data files were analysed initially with Access and SPSS (version 10). Random effects logistic regression (Stata, version 6) was used to analyse each binary outcome at the patient level, taking into account that the unit of randomisation was the practice.

\section{RESULTS}

\section{Study sample}

Initially, 603 patients were identified in 89 practices, as shown in fig l. One hundred and thirty four patients did not meet the inclusion criteria when their records were reviewed; 112 had had an episode of anaemia within the previous 12 months and 22 were women aged under 50 or had received an incorrect prompt for their practice. A further 38 sets of notes were unavailable.

Table 1 describes the baseline characteristics of the 431 patients included in the analyses.

\section{Investigation into the cause of the IDA}

Table 2 illustrates the investigations undertaken to establish a cause for the anaemia. Upper gastrointestinal investigations include upper endoscopies (120, 54 with duodenal biopsy) and barium meals (11). Lower gastrointestinal investigations include barium enemas (131), colonoscopies (15), flexible sigmoidoscopies (17), and rigid sigmoidoscopies (32). In those patients having only a single test, the prompt did cause a trend towards lower tract investigation; in the control arm 26 patients had upper tract investigations and 21 lower investigations, whereas in the intervention arm only 10 had upper and 42 had lower bowel studies. However, using our criteria for adequate investigations, the prompt did not improve the management of patients as 100/204 (49\%) patients in the control group had adequate investigation, compared with 103/227 $(45 \%)$ in the intervention arm (odds ratio 0.88, 95\% 
Table 1 Presenting characteristics of patients; values are number (\%) except where stated otherwise

\begin{tabular}{|c|c|c|c|}
\hline & $\begin{array}{l}\text { Control } \\
\text { arm }\end{array}$ & $\begin{array}{l}\text { Intervention } \\
\text { arm }\end{array}$ & Total \\
\hline $\begin{array}{l}\text { Number of practices } \\
\text { Number of GPs } \\
\text { Number of patients }\end{array}$ & $\begin{array}{l}33 \\
111 \\
204\end{array}$ & $\begin{array}{l}46 \\
131 \\
227\end{array}$ & $\begin{array}{l}79 \\
242 \\
431\end{array}$ \\
\hline $\begin{array}{l}\text { Sex distribution } \\
\text { Men } \\
\text { Women }\end{array}$ & $\begin{array}{l}73(36) \\
131(64)\end{array}$ & $\begin{array}{l}81(36) \\
146(64)\end{array}$ & $\begin{array}{l}154(36) \\
277(64)\end{array}$ \\
\hline $\begin{array}{l}\text { Age group (years) } \\
<50 \\
50-69 \\
70-79 \\
80-89 \\
>90\end{array}$ & $\begin{array}{l}11(5) \\
67(33) \\
71(35) \\
48(24) \\
7(3)\end{array}$ & $\begin{array}{l}9(4) \\
62(27) \\
89(39) \\
56(24) \\
11(5)\end{array}$ & $\begin{array}{l}20(5) \\
129(30) \\
160(37) \\
104(24) \\
18(4)\end{array}$ \\
\hline $\begin{array}{l}\text { Severity of anaemia (hae } \\
\text { Mild }(\geqslant 90 \mathrm{~g} / \mathrm{l}) \\
\text { Moderate }(70-89 \mathrm{~g} / \mathrm{l}) \\
\text { Severe }(\leqslant 69 \mathrm{~g} / \mathrm{l})\end{array}$ & $\begin{array}{l}\text { oglobin) } \\
104(51) \\
67(33) \\
33(16)\end{array}$ & $\begin{array}{l}127(56) \\
72(32) \\
28(12)\end{array}$ & $\begin{array}{l}231(54) \\
139(32) \\
61(14)\end{array}$ \\
\hline $\begin{array}{l}\text { On aspirin } \\
\text { On NSAIDS }\end{array}$ & $\begin{array}{l}42(21) \\
29(14)\end{array}$ & $\begin{array}{l}39(17) \\
37 \text { (16) }\end{array}$ & $\begin{array}{l}81(19) \\
66(15)\end{array}$ \\
\hline $\begin{array}{l}\text { Management* } \\
\text { GP alone } \\
\text { Shared } \\
\text { Hospital }\end{array}$ & $\begin{array}{l}102(50) \\
82(40) \\
20(10)\end{array}$ & $\begin{array}{l}123(54) \\
93(41) \\
11(5)\end{array}$ & $\begin{array}{l}225(52) \\
175(41) \\
31(7)\end{array}$ \\
\hline
\end{tabular}

GP, general practitioner; NSAIDs, non-steroidal anti-inflammatory drugs.

*Care during the first three months after identification of the anaemia: GP alone $=$ all treatment and investigations managed by GP; shared = GP care with non-urgent referral to hospital; hospital =

urgent/immediate admission and outpatient care.

confidence interval (CI) 0.60 to $1.29, \mathrm{p}=0.52$; see table 2); 140 $(39 \%)$ patients who were apparently fit were not considered for investigation at all.

\section{Iron prescription and follow up}

Table 3 illustrates the effect of the prompt on the prescription of an adequate course of iron therapy. The data refer to documented evidence of a prescription for iron and exclude six patients who were told to buy iron over the counter. The initial prescribing of iron, and in an adequate dose, was significantly improved following the prompt but there was no effect on the further monitoring of the blood count or on having a normal haemoglobin documented within the subsequent year.

\section{Clinical outcomes at 12 months}

Table 4 shows the pathology to which the IDA was attributed, 12 months after the date of the anaemia. One hundred and twenty eight patients (30\%) had a confirmed pathology likely to have contributed to the anaemia, with no difference between the trial arms.

Of the 54 cancers identified, 41 were in the gastrointestinal tract. Six of the nine patients with gastric cancer had an upper gastrointestinal investigation and one had upper and lower. One died before investigation, and further investigation was not thought appropriate for another.

Of the 32 lower gastrointestinal cancers, two were recurrent tumours at the time of the IDA. Twelve patients had lower gastrointestinal investigations only and 10 had upper and lower; one patient died before investigation, one refused investigation, two were considered unfit, and four had no investigations at the time. One patient had had upper and lower investigations but the enema was noted to be unsatisfactory and it was suggested that if the anaemia recurred a repeat was indicated. Overall, 29 of the 41 gastrointestinal cancers (22 lower, seven upper) were found as a result of satisfactory gastrointestinal investigations.

Sixty six patients died within a year of the diagnosis of anaemia, including 21 from gastrointestinal cancer, six from other gastrointestinal disease, and six from other cancers.

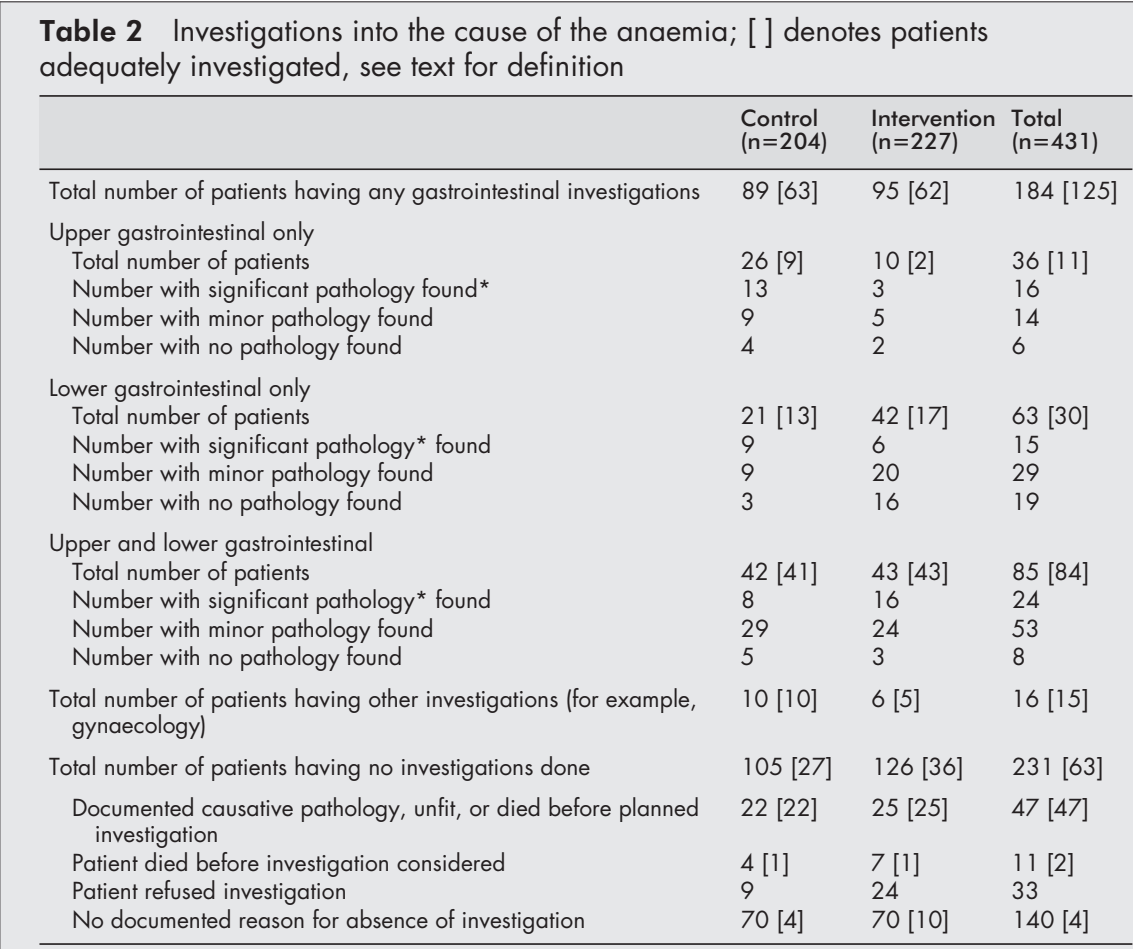

*Significant pathology includes upper or lower carcinoma, active peptic ulceration, coeliac disease inflammatory bowel disease, colon polyps, and angiodysplasia. All other abnormalities are classed as minor pathology. 
Table 3 Documented prescription of oral iron, monitoring, and resolution of the anaemia

\begin{tabular}{lllll}
\hline & $\begin{array}{l}\text { No (\%) } \\
\text { control arm } \\
(\mathrm{n}=204)\end{array}$ & $\begin{array}{l}\text { No (\%) } \\
\text { intervention arm } \\
(\mathrm{n}=227)\end{array}$ & $\begin{array}{l}\text { Odds ratio } \\
(95 \% \mathrm{CI})\end{array}$ & $\begin{array}{l}\text { Test statistic } \\
\text { (p value) }\end{array}$ \\
\hline Oral iron prescribed & $162(79)$ & $203(89)$ & $2.19(1.27$ to 3.77) & 0.005 \\
Adequate dose of iron & $145(71)$ & $188(83)$ & $1.96(1.24$ to 3.10) & 0.004 \\
Adequate course of iron & $74(36)$ & $90(40)$ & $1.26(0.77$ to 2.07) & 0.36 \\
FBC repeated within 6 weeks & $72(35)$ & $72(32)$ & $0.85(0.57$ to 1.27$)$ & 0.43 \\
Normal haemoglobin within 1 year & $117(57)$ & $138(61)$ & $1.16(0.74$ to 1.80$)$ & 0.52 \\
No follow up counts at all & $15(7)$ & $18(8)$ & & \\
\hline FBC, full blood count. & & & &
\end{tabular}

Table 4 Pathology related to cause of anaemia at one year



\section{DISCUSSION}

Overall the management and follow up of patients presenting to their general practitioners with IDA is suboptimal with a quarter of patients otherwise fit for investigation having no consideration of further tests at all and $40 \%$ not having a normal haemoglobin recorded within 12 months. A computerised prompt for the management of patients with iron deficiency anaemia resulted in a small but significant improvement in the initial prescribing of iron but failed to improve the follow up and adequacy of investigation undertaken to find its cause.

We consider that the levels of haemoglobin, mean cell volume, and red cell count chosen were reasonable indicators of iron deficiency and that patients should have been managed accordingly. The mean cell volume was chosen rather than the mean corpuscular haemoglobin as this is the index general practitioners would use to define the type of anaemia. We did not require confirmation of iron deficiency as a normal serum ferritin should not preclude further investigation of a hypochromic microcytic anaemia. The prevalence of haemoglobinopathies is small in the districts concerned and patients with a previous anaemia within the year were ineligible, thus excluding the majority of cases of anaemia of chronic disease.
Our patient population differs from those of most other studies which have looked at outcomes of patients with IDA referred to hospitals, ${ }^{6-11}$ as it includes patients who were unlikely to benefit from investigation $(91 / 431,21 \%)$ including patients who refused tests $(33 / 431,8 \%)$.

Patients who have accepted hospital referral are generally prepared to be investigated, and comparisons between expected levels of investigation in our study and those of hospital patients must take this into account. Although we classed refusal of investigation as an inadequate outcome, some general practitioners had evidently tried hard to persuade their patients of the need for investigation.

In developing our criteria for determining adequate management, we allowed for comorbidity of the patient, as far as that could be assessed from the notes. We included investigations resulting in a diagnosis of extensive diverticular disease in elderly patients without upper gastrointestinal symptoms as satisfactory, because our prompt had suggested excluding a colorectal cause and many general practitioners would not feel it necessary to proceed to other investigations after receiving this result. The standard of reporting of investigative procedures by hospital clinicians was extremely variable, rarely mentioning a possible cause for the anaemia, and 
on several occasions will have influenced the general practitioner not to proceed with further investigation, although serious disease had not been excluded. Using our criteria, the prompt had no effect on increasing the proportion of patients adequately investigated.

The prompt did improve the initial prescribing of an adequate dose of oral iron, but subsequent monitoring and duration of therapy were not influenced, with only $30 \%$ of patients having a repeat count within six weeks and only $60 \%$ a normal haemoglobin recorded within the year. Patients' non-compliance with iron therapy or follow up visits may have contributed to these low levels of monitoring and resolution of the anaemia. ${ }^{17}$

Pathology laboratories are well placed to issue simple computerised prompts to assist with further management of patients. A simple message has been shown to influence general practitioner referrals for radiology, ${ }^{18}$ and there have been numerous other reviews of guideline implementation which show that different interventions will be appropriate for different contexts. ${ }^{19-22}$

Other studies have considered the lack of uptake of guidelines by general practitioners and suggested key criteria for improving their use including brevity, simplicity, and ease of retrieval. ${ }^{23-26}$ Our prompt was simple and presumably readily available at the first follow up after the presentation with the anaemia, when it did influence the prescription for iron. However the lack of referral to the original form after the first follow up and possible lack of a clear management plan in the case record may have contributed to the lack of influence on subsequent management, including further assessment of the haemoglobin level after treatment.

Twelve months after the incident anaemia only 128/431 $(30 \%)$ patients had a confirmed diagnosis that may have contributed to the anaemia. The small number of patients (5) with coeliac disease detected reflects the small number of duodenal biopsies performed even if a gastroduodenoscopy was carried out. In 1997 the number of requests from general practitioners for gliadin and endomysial antibody tests for coeliac disease was insignificant. Other studies of coeliac disease have shown a prevalence of $3 \%-5 \%$ in an IDA population and suggest substantial underdiagnosis. ${ }^{27} 28$

Twenty one of the 30 new colorectal cancers diagnosed within 12 months were found in the $125(17 \%)$ patients who had adequate gastrointestinal investigations when the anaemia was found, giving a prevalence similar to other studies of patients with IDA. ${ }^{6-9} 29$ A number of patients who had partial or no investigation of the anaemia were later found to have cancer.

Our study is the first large community based project to show that $50 \%$ of cases of IDA are managed solely by their general practitioner, but the standard of treatment and follow up is not improved by a decision support system which had only a transient effect on clinical behaviour. It also raises serious concerns about the understanding among many general practitioners in our local health districts of the significance of IDA in men and older women. Other ways of influencing this and patient outcomes need to be considered in order to improve the early diagnosis of colorectal disease and reduce the morbidity associated with chronic anaemia. We plan to extend the follow up of all patients without a confirmed diagnosis, with particular reference to subsequent diagnoses of cancer.

\section{ACKNOWLEDGEMENTS}

We would like to thank the local general practitioners and staff in participating practices, without whose help this study could not have proceeded. We are particularly grateful to Mr Mick Edwards and the laboratory staff at both hospitals for their advice and support during the study. We also thank the patient record managers at the health authorities and the hospitals for access to records and Dr Michael Hewitt, Manager of the Audit, Evaluation and Research Department at King's Mill, for his advice and help with the database.
The trial was supported by the National Research and Development Programme, "The evaluation of methods to promote the implementation of research findings".

\section{Authors' affiliations}

E C M Logan, J M Yates, King's Mill Centre for Healthcare Services, Sutton-in-Ashfield, Nottinghamshire

R M Stewart, Chesterfield and North Derbyshire Royal Hospital, Calow, Derbyshire

K Fielding, London School of Hygiene and Tropical Medicine, London D Kendrick, Division of General Practice, School of Community Health Sciences, University Park, Nottingham

\section{REFERENCES}

1 Morbidity Statistics from General Practice. Fourth National Study 1991-1992. London: OPCS, 1995.

2 Smith A, McCarthy $\mathrm{H}$. Guide to the investigation and treatment of anaemia. Prescriber 1998;5:37-64.

3 British Medical Association and the Royal Pharmaceutical Societ of Great Britain. British national formulary. Section 9.1.1. Iron deficiency anaemias. London: BMA and the Royal Pharmaceutical Societ of Great Britain, March 1998 (No 35).

4 Frewin $R$, Henson A, Provan D. ABC of clinical haematology: iron deficiency anaemia. BM 1997;314:360-3

5 Goddard F, Mclntyre AS, for the British Society of Gastroenterology. Guidelines for the management of iron deficiency anaemia. Gut 2000;46(suppl IV): 1-5.

6 Joosten E, Ghesquiere B, Linthoudt $\mathrm{H}$, et al. Upper and lower gastrointestinal evaluation of elderly inpatients who are iron deficient. Am J Med 1999;107:24-9.

7 Rockey DC, Cello JP. Evaluation of the gastrointestinal tract in patients with iron deficiency anaemia. N Engl J Med 1993;329:1691-5.

8 Mclntyre AS, Long RG. Prospective survey of investigations in outpatients referred with iron deficiency anaemia. Gut 1993;34:1102-7.

9 Cook IJ, Pavli P, Riley JW, et al. Gastrointestinal investigation of iron deficiency anaemia. BM 1986;292:1380-2.

10 Willoughby JMT, Laitner SM. Audit of the investigation of iron deficiency anaemia in a district general hospital, with sample guidelines for future practice. Postgrad Med J 2000;76:218-22.

11 Wilcox CM, Alexander LN, Clark WS. Prospective evaluation of the gastrointestinal tract in patients with iron deficiency anaemia and no systemic or gastrointestinal symptoms or signs. Am J Med 1997; 103:405-9.

12 Fry J. Clinical patterns and course of anaemias in general practice. $B M$ 1961;1732-6 (30 Dec)

13 Stellon AJ, Kenwright SE. Iron deficiency anaemia in general practice: presentation and investigation. Br J Clin Pract 1997:51:78-80.

14 Waller DG, Smith AG. Attitudes to prescribing iron supplements in general practice. BM 1987;294:94-6.

15 Lucas CA, Logan ECM, Logan RFA. Audit of the investigation and outcome of iron deficiency anaemia in one health district. J $R$ Coll Phys Lond 1996:30:33-5.

16 Donner A, Birkett N, Buck C. Randomisation by cluster: sample size requirements and analysis. Am J Epidemiol 1981;114:906-14

17 Beardon PHG, McGilchrist MM, McKendrick AD, et al. Primary non-compliance with prescribed medication in primary care. BM 1993;307:846-8.

18 Grimshaw JM, Russell IT. Effect of clinical guidelines on medical practice: a systematic review of rigorous evaluations. Lancet 1993;342:1317-22.

19 Eccles M, Steen N, Grimshaw J, et al. Effect of audit and feedback, and reminder messages on primary-care radiology referrals: a randomised trial. Lancet 2001;357:1406-9.

20 NHS Centre for Reviews and Dissemination. Getting evidence into practice. Effective Health Care Bulletin 1999;5(1).

21 Wensing $M$, van der Weijden T, Grol R. Implementing guidelines and innovations in general practice: which interventions are effective? $\mathrm{Br} J$ Gen Pract 1998;48:991-7.

22 Thompson C, Kinmonth AL, Stevens L, et al. Effects of a clinical-practice guideline on detection and outcome of depression in primary care: Hampshire Depression Project randomised controlled trial. Lancet 2000;355: 185-91.

23 Langley C, Faulkner A, Watkins C, et al. Use of guidelines in primary care: practitioners' perspectives. Fam Pract 1998;15:105-1 1 .

24 Hibble A, Kanka D, Pencheon D, et al. Guidelines in general practice the new Tower of Babel? BM 1998;317:862-3.

25 Watkins C, Harvey I, Langley C, et al. General practitioners' use of guidelines in the consultation and their attitudes to them. Br J Gen Pract 1999;49:11-15.

26 Siriwardena AN. Clinical guidelines in primary care: a survey of general practitioners' attitudes and behaviour. Br J Gen Pract 1995:45:643-7.

27 Hin H, Bird G, Fisher P, et al. Coeliac disease in primary care: case finding study. BM 1999;318:164-7.

28 Unsworth DJ, Lock RJ, Harvey RF. Improving the diagnosis of coeliac disease in anaemic women. Br J Haematol 2000;1 11:898-901.

29 Till S, Grundman M. Prevalence of concomitant disease in patients with iron deficiency anaemia. BM 1997;314:206-8. 